\title{
PROFIL DAN PROBABILITAS KEJADIAN GANGGUAN DURASI TIDUR-PERSEPSI KUALITAS TIDUR MAHASISWA KEDOKTERAN: STUDI FORMATIF
}

\author{
Vania Angeline Bachtiar ${ }^{1}$, \\ Perigrinus H. Sebong ${ }^{2}$
}

\author{
${ }^{1}$ Departemen Neurologi, Fakultas Kedokteran, Universitas Katolik Soegijapranata, Semarang, Indonesia \\ ${ }^{2}$ Departemen Ilmu Kesehatan Masyarakat, Fakultas Kedokteran Universitas Katolik Soegijapranata \\ Semarang, Indonesia \\ Korespondensi Penulis: \\ Nama $\quad$ : dr. Vania Angeline Bachtiar, Sp.N \\ Alamat : Jl. Pawiyatan Luhur IV No. 1 Bendan Duwur - Semarang 50234 - Indonesia \\ Nomor Telepon : 8441555 (hunting) \\ Email : vania@unika.ac.id
}

\begin{abstract}
Abstrak
Latar Belakang : Durasi tidur yang rendah dan kualitas tidur yang buruk dapat mempengaruhi kognitif dan psikomotor mahasiswa kedokteran. Jika profil tidur pada mahasiswa tidak segera diketahui dan diatasi maka akan berdampak pada kesehatan mereka dikemudian hari. Penelitian ini bertujuan menggambarkan profil durasi tidur dan persepsi kualitas tidur mahasiswa kemudian memberi input manajemen tidur yang baik.

Desain Penelitian : Jenis penelitian ini adalah studi formatif dengan responden mahasiswa Fakultas Kedokteran Unika Soegijapranata sebanyak 42 orang dipilih secara purposive sampling. Pengambilan data dilakukan di akhir semester ganjil tahun ajaran 2020-2021 dengan menggunakan google form. Analisis data dilakukan dengan menggunakan analisis univariat dan perhitungan mean dan standar deviasi untuk data numerik serta dilakukan uji proyeksi resiko.

Hasil : Sebanyak 63,3\% responden perempuan dan 83,3\% laki-laki menilai kualitas tidur mereka baik dan $75 \%$ responden yang duduk di semester 2 dan $63,6 \%$ responden semester 4 menilai memiliki kualitas tidur yang baik. Rata-rata durasi tidur responden adalah 5,7 jam per malam dan responden perempuan lebih dominan mengalami durasi tidur $<7$ jam/malam $(0,75)$. Probabilitas meningkatnya prevalensi gangguan durasi tidur akan semakin memburuk apabila tidak dilakukan intervensi pengendalian gangguan tidur.

Kesimpulan : Persepsi terhadap kualitas tidur tidak sejalan dengan durasi tidur yang dilaporkan oleh responden. Oleh karena itu dibutuhkan intervensi berupa managemen waktu tidur dan sleep hygiene untuk mengendalikan prevalensi gangguan tidur di kalangan mahasiswa kedokteran.
\end{abstract}

Kata kunci: gangguan tidur, sleep hygiene, durasi tidur, manajemen waktu tidur.

\section{Pendahuluan}

Tidur merupakan kebutuhan yang sangat esensial bagi manusia, karena bagian dari pemulihan tubuh dan pikiran. ${ }^{1}$ Kebiasaan tidur yang sehat membutuhkan durasi yang cukup, waktu yang tepat, kualitas yang baik, keteraturan, dan tidak adanya gangguan. Berbagai penelitian telah menunjukkan bahwa durasi tidur yang cukup dapat meningkatkan perhatian, perilaku, fungsi kognitif, dan pengelolaan emosional yang lebih baik. ${ }^{2}$ 
Hasil analisis epidemiologis menunjukkan bahwa durasi tidur yang kurang baik berkorelasi dengan risiko hipertensi, diabetes, obesitas, dan bahkan kematian. ${ }^{3,4}$ Sesesorang dengan durasi tidur yang kurang dapat menyebabkan kualitas tidur yang buruk yang berakibat menderita risiko gangguan memori dan menurunnya fungsi kognitif. Selain itu, beberapa penelitian sebelumnya menunjukkan bahwa durasi tidur yang pendek dan kualitas tidur yang buruk dikaitkan dengan prevalensi gejala depresi yang lebih tinggi pada remaja dan mahasiswa. Beberapa penelitian melaporkan bahwa antara 43\%, 58\% dan 88\% mahasiswa kedokteran memiliki kualitas tidur yang buruk karena stres dan kecemasan berkepanjangan akibat kurikulum pendidikan yang ekstensif serta sleep hygene yang buruk. Kualitas tidur yang buruk di kalangan mahasiswa kedokteran biasanya mengakibatkan kurang tidur yang bermanifestasi sebagai kantuk berlebihan di siang hari. Kurang tidur kronis yang mengakibatkan kualitas tidur yang buruk dapat mempengaruhi kognitif dan psikomotor mahasiswa kedokteran. ${ }^{5-7}$ Jika profil tidur pada mahasiswa tidak segera diketahui dan diatasi maka akan berdampak pada kesehatan mereka dikemudian hari.

Di Indonesia, terdapat banyak penelitian yang mengkaji tentang gangguan tidur pada mahasiswa. Sebagai contoh, studi yang menemukan prevalensi ganguan tidur pada mahasiswa terus meningkat terutama selama masa pandemi COVID-19. ${ }^{8}$ Selain itu studi lain juga telah mengkaji pola tidur dan kelelahan dengan berbagai faktor yang berkontribusi terhadap kualitas tidur yang buruk pada mahasiswa. ${ }^{9}$ Namun, belum banyak studi yang memberikan input dan inisiasi untuk manajemen kualitas tidur. Kesenjangan ini menjadi masalah penting karena gaya hidup dan kebiasaan tidur mahasiswa berbeda dengan populasi umum. ${ }^{10}$ Penelitian ini bertujuan menggambarkan profil durasi tidur dan persepsi kualitas tidur mahasiswa kemudian memberi input manajemen tidur yang baik.

\section{Metode}

Jenis penelitian ini adalah studi formatif deskriptif dengan menggunakan metode survey. Populasi penelitian adalah mahasiswa Fakultas Kedokteran (FK) Universitas Katolik Soegijapranata. Subjek penelitian sebanyak 42 orang dipilih secara purposive sampling dan menyatakan kesediaannya mengisi survey melalui informed consent. Waktu pengambilan data di akhir semester ganjil tahun ajaran 2020-2021 yaitu di bulan Desember 2020. 


\section{Instrumen dan Pengukuran}

Pengumpulan data dilakukan dengan menggunakan google form. Data yang disurvey adalah durasi tidur dan persepsi tentang kualitas tidur mahasiswa. Jumlah pertanyaan yang diberikan yaitu 3 pertanyaan yang terdiri dari 2 pertanyaan terbuka dan 1 pertanyaan tertutup. Penelitian ini menggunakan analisis statistik deskriptif untuk menggambarkan data frekuensi. Analisis dilakukan dengan menggunakan analisis univariat dan perhitungan mean dan standar deviasi untuk data numerik, menggunakan IBM Stata. 19. Guna mengetahui probabilitas terjadinya peningkatan prevalensi kejadian gangguan tidur, maka dilakukan uji faktor resiko.

\section{Hasil}

Total terdapat 42 responden terlibat dalam penelitian ini, 71,4\% responden berjenis kelamin perempuan dan 28,5\% berjenis kelamin laki-laki, 47,6\% sedang duduk di semester 2 dan $52,3 \%$ responden duduk di semester 4 . Berdasarkan grafik 1, dari diketahui $63,3 \%$ responden perempuan dan $83,3 \%$ laki-laki menilai kualitas tidur mereka baik dan $75 \%$ responden yang duduk di semester 2 dan 63,6\% responden semester 4 menilai memiliki kualitas tidur yang baik.

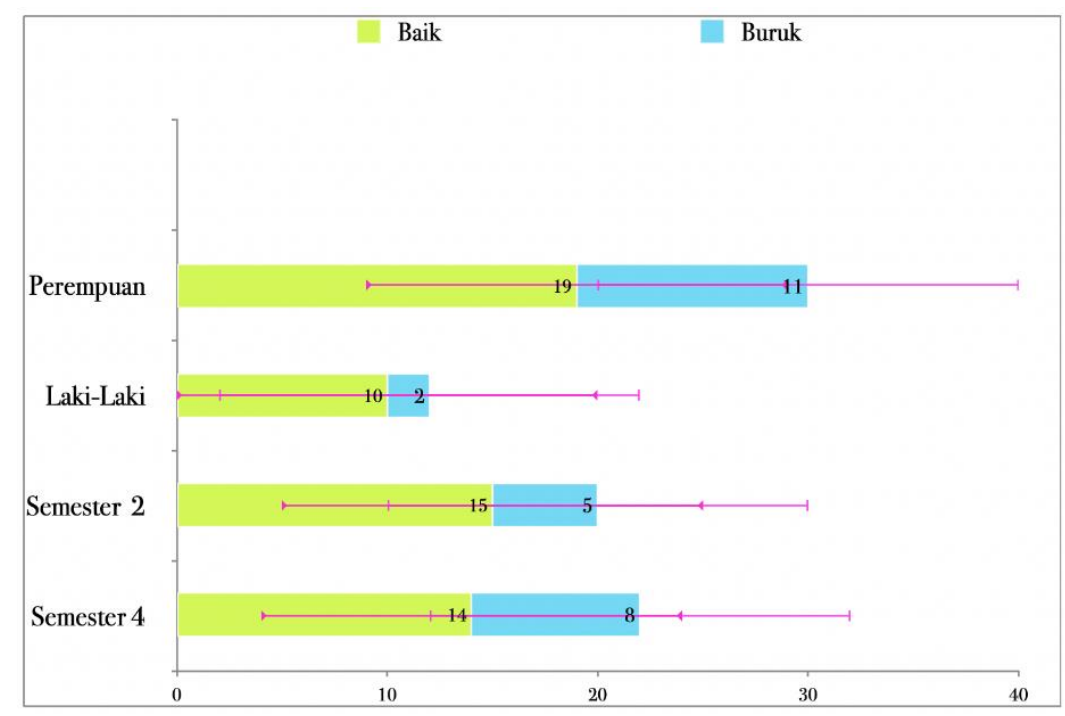

Grafik 1. Sebaran Persepsi Kualitas Tidur Berdasarkan Jenis Kelamin dan Semester 
Rata-rata durasi tidur responden adalah 5,7 jam per malam, dengan durasi tidur tertinggi adalah 7,7 jam per malam dan durasi tidur terendah adalah 1,5 jam per malam (grafik 2).

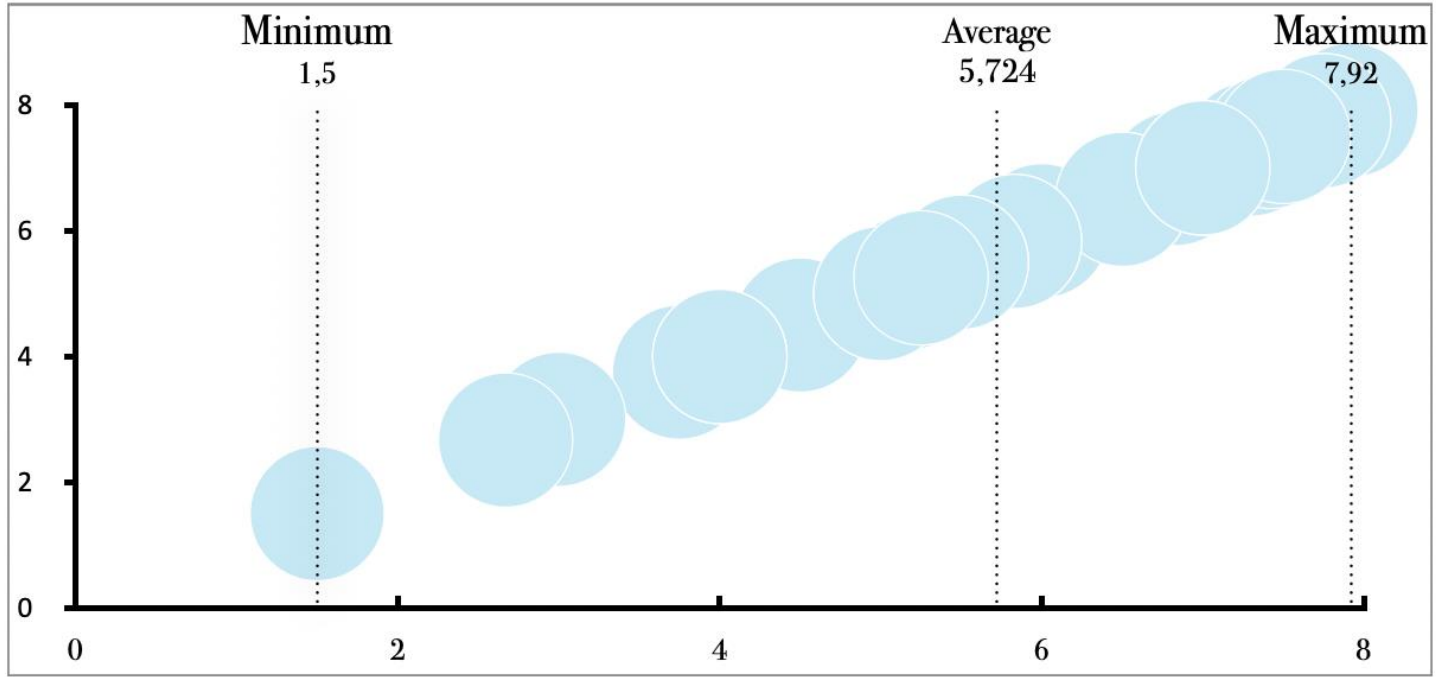

Grafik 2. Profil Durasi Tidur Responden

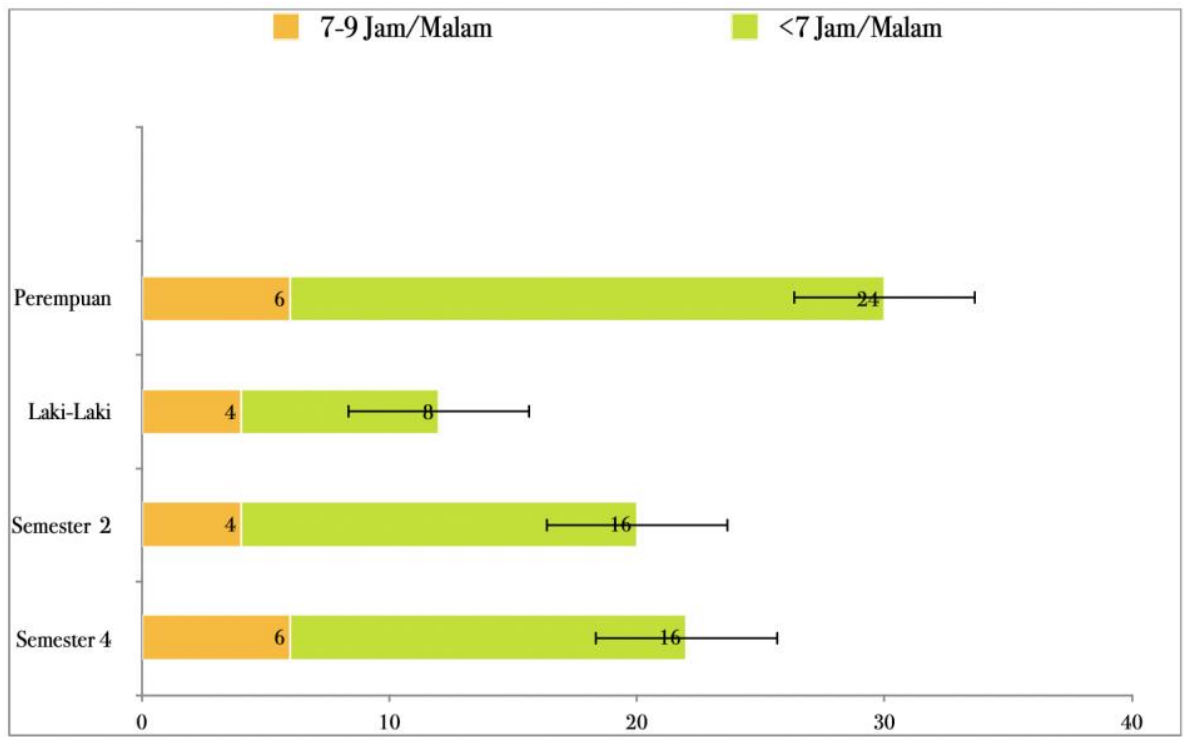

Grafik 3. Profil Durasi Tidur Mahasiswa Berdasarkan Jenis Kelamin dan

Berdasarkan grafik 3, diketahui responden perempuan lebih dominan mengalami durasi tidur $<7$ jam/malam $(0,75)$ sedangkan jumlah responden semester 2 dan 4 yang mengalami durasi tidur $<7$ jam/malam masing-masing sebanyak 16 responden. 
Guna mengetahui, resiko meningkatnya gangguan tidur pada mahasiswa secara keseluruhan, maka penelitian melakukan analisis lebih lanjut.

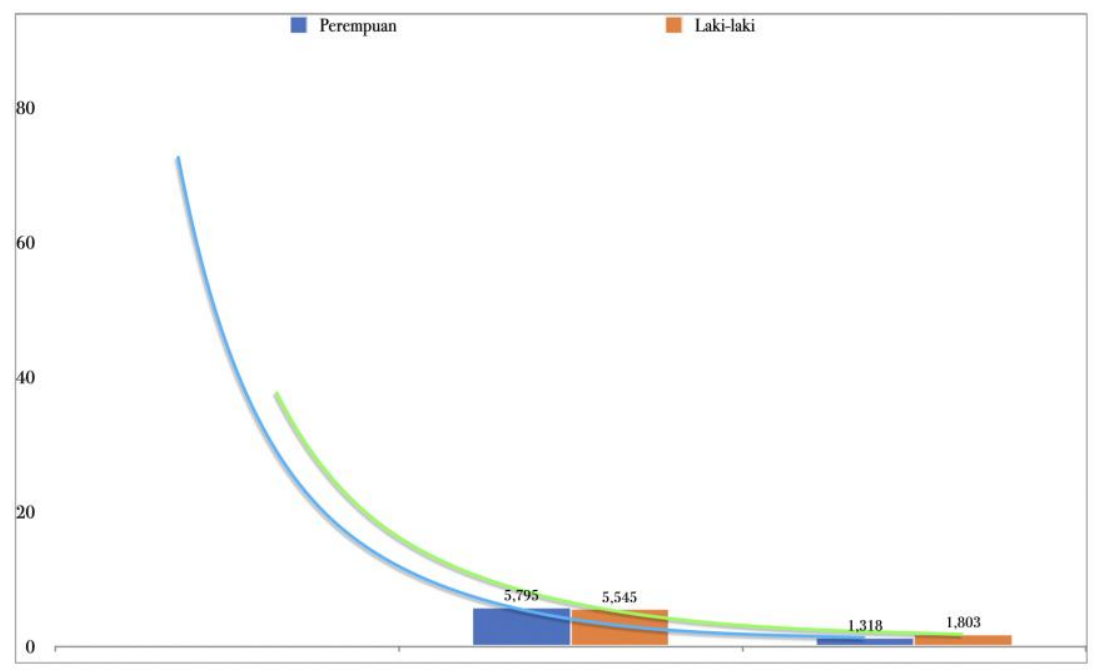

Grafik 4. Proyeksi Durasi Tidur Pada Mahasiswa FK Unika Soegijapranata

\section{Grafik 4. Proyeksi Durasi Tidur Pada Mahasiswa FK UNIKA Soegijapranata}

Berdasarkan hasil analisis risiko peningkatan gangguan durasi tidur, diketahui bahwa apabila tidak dilakukan intervensi (skenario 1) maka akan berpeluang meningkatnya prevalensi gangguan durasi tidur di kalangan mahasiswa. Hasil analisis lengkapnya disajikan pada grafik 4.

\section{Diskusi}

Persepsi terhadap buruknya kualitas tidur hanya dimiliki sebagian kecil responden sedangkan terlihat bahwa tiga per empat responden memiliki durasi tidur malam $<7 \mathrm{jam}$. Temuan ini sejalan dengan penelitian pada mahasiswa kedokteran di Ghana yaitu hanya 9\% yang menyatakan kualitas tidur mereka buruk dengan rerata durasi tidur 5,7 $\pm 1,2$ jam per malam. ${ }^{7}$ Beberapa penelitian lain juga menemukan durasi tidur yang kurang pada sebagian besar mahasiswa FK Unika Soegijapranata. ${ }^{11}$

Responden semester 4 lebih sedikit yang memiliki persepsi bahwa kualitas tidur mereka baik dibanding responden semester 2. Hal ini dapat memperlihatkan bahwa responden dengan semester lebih tinggi memiliki pengetahuan lebih tentang kualitas tidur, sejalan dengan penelitian Ahmed tahun 2017 tentang pengetahuan dan perilaku tidur pada 261 mahasiswa kedokteran. ${ }^{11}$ 
Hasil proyeksi durasi tidur memperlihatkan adanya risiko peningkatan jumlah gangguan durasi tidur malam pada responden. Ganggaun durasi tidur umumnya lebih banyak dialami oleh orang dewasa muda. Jika kondisi ini diabaikan maka berpotensi mengakibatkan gangguan kesehatan lainnya seperti penyakit kardiovaskular dan obesitas, oleh karena itu dibutuhkan input manajemen tidur yang baik. Kebutuhan tidur orang dewasa muda adalah 7-9 jam per malam dengan siklus yang regular agar dapat mempertahankan kesehatan yang optimal. ${ }^{12,13}$ Sebuah survey kepada mahasiswa kedokteran menunjukkan 71,5\% mahasiswa mengetahui bahwa mereka membutuhkan tidur $>7$ jam per malam namun hanya seperempat yang tetap menerapkan tidur dengan durasi minimal 7 jam. ${ }^{11}$ Pada sisi yang lain, mahasiswa kedokteran mengetahui sleep hygiene lebih baik dibandingkan mahasiswa fakultas lain, tetapi mereka tetap memiliki kualitas tidur yang lebih buruk. ${ }^{14}$

Beberapa faktor yang dapat menyebabkan gangguan tidur pada mahasiswa adalah academic stressors (kurikulum yang padat, frekuensi ujian yang tinggi, tuntutan terhadap performa akademik), psycological distress, social stressors (harapan orangtua yang tinggi dan tinggal jauh dari keluarga) dan health related stressors.$^{9,15-17}$ Walaupun penelitian ini hanya dilakukan pada 42 mahasiswa aktif dan hanya mengukur dari periode 1 bulan, tetapi temuan dari penelitian ini berguna untuk merancang strategi intervensi perbaikan kualitas tidur. Selain itu, penelitian ini juga memberikan estimasi beban peningkatan prevalensi gangguan tidur pada mahasiswa, sehingga dalam desain intervensi bisa diperhitungkan keterwakilan populasi target intervensi, cakupan intervensi dan berbagai faktor terkait termasuk kegiatan akademik mahasiswa.

Dengan mempertimbangkan aspek-aspek terdahulu maka sleep hygiene merupakan faktor penting yang mempengaruhi kualitas tidur..$^{6,14,18}$ Sleep hygiene yang baik dapat meningkatkan kualitas tidur. Beberapa di antaranya adalah sebagai berikut: 1) menghindari kafein, nikotin, dan alkohol menjelang waktu tidur, 2) menghindari tidur siang yang panjang, 3) mempertahankan waktu tidur dan bangun yang teratur, 4) menjaga kamar tidur tetap nyaman dan tenang, dan 5) kamar tidur hanya digunakan untuk tujuan beristirahat (tidur). ${ }^{18,6}$ Penelitian tentang penerapan sleep hygiene menunjukkan bahwa mahasiswa kedokteran tidak menerapkan perilaku sleep hygiene dengan benar. ${ }^{6,14}$ 


\section{Kesimpulan}

Berdasarkan analisis yang telah dilakukan, dapat disimpulkan bahwa terdapat perbedaan persentase persepsi kualitas tidur yang baik dengan lama durasi tidur nomal (ideal) yang direkomendasikan pada orang dewasa. Persepsi kualitas tidur tidak sejalan dengan durasi tidur yang dilaporkan oleh responden. Analisis resiko menunjukkan desain intervensi managemen waktu tidur dan sleep hygiene perlu dirancang dengan cermat dan terukur sehingga pada akhirnya bisa menekan bertambahnya prevalensi gangguan tidur di kalangan mahasiswa kedokteran FK Unika Soegijapranata.

\section{Persetujuan Etik}

Penelitian ini tidak menggunakan ethical clearance karena merupakan studi formatif.

\section{Ucapan Terima Kasih}

1. Universitas Soegipranata Semarang yang sudah memberikan dana sehingga kegiatan penelitian ini bisa terlaksana.

2. Program Studi Pendidikan Kedokteran, FK Unika Soegijapranata yang sudah memberikan izin pengambilan data dan intervensi.

\section{Daftar Pustaka}

1. Darien IL. Sleep disorder. American Academy Sleep Medicine. 2014. p. 12-34.

2. Paruthi S, Brooks LJ, D'Ambrosio D, Hall WA, Kotagal S, et al. Recommended Amount of Sleep for Pediatric Populations: A Consensus Statement of the American Academy of Sleep Medicine. J Clin Sleep Med. 2016; 12(6): 785-6.

3. Kim M-Y, Lee S, Myong YH, Lee YJ, Kim M-R, et al. Association between sleep duration and stroke prevalence in Korean adults: a crosssectional study. BMJ Open 2018;8:e021491.

4. Ogilvie RP dan Patel SR. The Epidemiology of Sleep and Obesity. Sleep Health. 2017;3(5):383-8

5. Anjum A, Bajwa MA dan Saeed R. Sleep Patterns: Among Medical and Non-Medical Student of University of Lahore, 2010-11. Professional Med J. 2014;21(1): 148-56

6. Yazdi Z, Loukzadeh Z, Moghaddam P, dan Jalilolghadr S. Sleep hygiene practices and their relation to sleep quality in medical students of Qazvin university of medical sciences. J Caring Sci 2016; 5 (2): 153-60. doi:10.15171/jcs.2016.016 
7. Lawson HJ, Mensah JTW, dan Nantogma SA. Evaluation of Sleep Patterns and Self-Reported Academic Performance among Medical Students at the University of Ghana School of Medicine and Dentistry. Hindawi Sleep Disorders, volume 2019, Article ID 1278579.

8. Windiani IGAT, Noviyani NMR, Adnyana IGANS, Murti NLSP, dan Soetjiningsih. Prevalence of Sleep Disorders in Adolescents and its Relation with Screen Time during the COVID-19 Pandemic Era. Open Access Maced J Med Sci. 2021; 9(B): 297-300

9. Alfian SD, Ng H, Destiani DP, dan Abdulah R. Psychological Distress Induces Poor Sleep Quality: A Cross-Sectional Study of Pharmacy Students in Bandung City, Indonesia. The Open Public Health Journal. 2018, volume 11

10. Li W, Yin J, Cai X, Cheng X, dan Wang Y. Association between sleep duration and quality and depressive symptoms among university students: A cross-sectional study. PLoS ONE. $2020 ; 15(9)$

11. Ahmed N, Sadat M dan Cukor D. Sleep Knowledge and Behaviors in Medical Students: Results of a Single Center Survey. Acad Psychiatry. 2017;41(5):674-8

12. Watson NF, Badr MS, Belenky G, Bliwise DL, Buxton OM, et al. Recommended amount of sleep for a healthy adult: a joint consensus statement of the American Academy of Sleep Medicine and Sleep Research Society. J Clin Sleep Med 2015;11(6):591-592.

13. Hirshkowitz M, Whiton K, Albert SM, Alessi C, Bruni O, et al. The National Sleep Foundation's sleep time duration recommendations: methodology and results summary. Sleep Health. 2015;1(1):40-43.

14. Al-Kandari S, et al, Association between sleep hygiene awareness and practice with sleep quality among Kuwait University students, Sleep Health (2017), http://dx.doi.org/10.1016/j.sleh.2017.06.004

15. Waqas A, Khan S, Sharif W, Khalid U dan Ali A. Association of academic stress with sleeping difficulties in medical students of a Pakistani medical school: a cross sectional survey. PeerJ. 2015; $3: \mathrm{e} 840$

16. Azad MC, Fraser K, Rumana N, Abdullah AF, Shahana N, et al. Sleep disturbances among medical students: a global perspective. J Clin Sleep Med 2015;11(1):69-74

17. Beck F, Léger D, Fressard L, Peretti-Watel P, dan Verger P. Covid-19 health crisis and lockdown associated with high level of sleep complaints and hypnotic uptake at the population level. J Sleep Res. 2020;00:e13119. https://doi.org/10.1111/jsr.13119

18. Brick CA, Seely DL dan Palermo M. Association Between Sleep Hygiene and Sleep Quality in Medical Students. Behav Sleep Med. 2010; 8(2): 113-121 